\title{
Chronic Subdural Hematoma Treated by Burr Holes and Closed Drainage System: A Review of 630 Cases
}

\author{
Miguel Gelabert-González Elena López-García Juan Fernández-Villa
}

Neurosurgical Service, Department of Surgery, Hospital Clínico de Santiago, University of Santiago de Compostela, Spain

\section{Key Words}

Chronic subdural hematoma $\cdot$ Markwalder grading system · Burr holes - Closed subdural drainage system

\begin{abstract}
Objectives: To study the clinical features and surgical results of patients with chronic subdural hematoma. Methods: A retrospective study of the records of 630 patients treated surgically for chronic subdural hematoma using a burr hole and closed drainage system was conducted. Results: Six hundred and thirty patients (438 males and 192 females) ranging from 12 to 100 years with a mean age of 66.7 years were identified. Upon admission, 242 (38\%) patients were in satisfactory condition (grades 0-1), 262 (42\%) patients were at grade 2 and $126(20 \%)$ were at grades 3 or 4 . In $5.3 \%$ of the patients, surgical intervention was required to remove a recurring hematoma. In $77 \%$ of the patients, the results achieved could be graded as good (grades $0-1$ ), with mortality being $2.5 \%$. The only factor affecting the outcome was the grade at admission $(p<0.05)$. Conclusion: A simple and routinely used burr hole procedure either under local or general anesthesia with a closed drainage system is a safe and effective procedure for the treatment of chronic subdural hematoma.
\end{abstract}

Copyright (c) 2001 S. Karger AG, Basel

\section{Introduction}

Chronic subdural hematoma (CSDH) is one of the commonest conditions requiring neurosurgical intervention. Many neurosurgeons regard $\mathrm{CSDH}$ as a common and somewhat uninsteresting condition. Most patients are elderly, and generally do well after relatively simple surgical treatment, which is usually left in the hands of neurosurgical trainees [1]. The incidence of CSDH is likely to rise with the increase in life expectancy.

Surgical treatments for CSDH include removal of the hematoma via craniotomy, irrigation by burr hole with or without drainage, drainage by a closed system without irrigation, subdural-peritoneal shunt, neuroendoscopic evacuation, etc. The purpose of this article is to present our experience with the surgical management of 630 patients with CSDH using a burr hole and a closed drainage system.

\section{Patients and Methods}

Between 1980 and 1999, 682 patients with CSDH were treated surgically at the Clinical Hospital of Santiago de Compostela, Spain. This series represents the total experience of our neurosurgical unit in handling 630 out of the 682 patients with CSDH managed via burr holes with a closed drainage system. The patients that were excluded were 31 operated on by craniotomy, 12 with prior craniotomy for traumatic intracranial hemorrhage, and 9 cases with an incomplete clinical history. The clinical conditions of all the participants were graded in a similar fashion using the most common neurologic grad-

\begin{tabular}{ll}
\hline KARGER & ( ) 2001 S. Karger AG, Basel \\
Fax +4161306 12 34 & 1011-7571/01/0101-0041\$17.50/0 \\
$\begin{array}{l}\text { E-Mail karger@karger.ch } \\
\text { www.karger.com }\end{array}$ & $\begin{array}{l}\text { Accessible online at: } \\
\text { www.karger.com/journals/mpp }\end{array}$
\end{tabular}

Dr. Miguel Gelabert-González

Neurosurgical Service

Hospital Clínico, La Choupana

E-15706 Santiago de Compostela (Spain)

Tel. +34 981 950331, E-Mail cimigego@usc.es 
Table 1. The age and clinical state of patients on admission

\begin{tabular}{lrrrrrr}
\hline \multirow{2}{*}{$\begin{array}{l}\text { Age } \\
\text { years }\end{array}$} & \multicolumn{7}{c}{ Clinical grade } \\
\cline { 2 - 7 } & 0 & 1 & 2 & 3 & 4 & total \\
\hline$<30$ & 0 & 2 & 1 & 2 & 0 & 5 \\
$31-40$ & 1 & 28 & 27 & 15 & 1 & 72 \\
$41-50$ & 2 & 34 & 53 & 21 & 2 & 112 \\
$51-60$ & 0 & 38 & 41 & 17 & 6 & 102 \\
$61-70$ & 4 & 46 & 49 & 22 & 3 & 124 \\
$71-80$ & 3 & 51 & 51 & 15 & 7 & 127 \\
$>81$ & 2 & 31 & 40 & 14 & 1 & 88 \\
\hline Total & 12 & 230 & 262 & 106 & 20 & 630 \\
\hline
\end{tabular}

ing system for $\mathrm{CSDH}$, proposed by Markwalder [2]: grade 0: no neurologic deficits; grade 1: mild symptoms such as headache, absent or mild neurologic deficits such as reflex asymmetry; grade 2: drowsiness or disorientation with variable neurologic deficits such as hemiparesis; grade 3: stupor, but appropriate responses to noxious stimuli, severe focal signs such as hemiplegia; grade 4: coma with an absence of motor response to painful stimuli, decerebrate or decorticate posturing.

All patients were diagnosed by computed tomography (CT) and were identified as types I-IV by CT, according to the classification system developed by Lanksch et al. [3] (hypodense hematomas, hematomas of varying density, isodense or slightly hyperdense hematomas). A further 10 cases were diagnosed by magnetic resonance (MR) imaging. Surgery was performed under local anesthesia; however, a few were performed under general anesthesia. The surgical technique included one burr hole overlying the subdural collection. The dura mater was shrunk with monopolar or bipolar coagulation to leave a permanent defect. The membrane was resected to an extent permitting evacuation of the hematoma. Resection of the internal membrane was not attempted. The subdural space was rinsed with a physiological saline solution. A round Jackson-Pratt drain (American Heyer-Schulte Co., Goleta, Calif., USA) [4] was installed and exteriorized through a separate stab wound. The subdural drain was left for 2-5 days postoperatively, depending on the amount of actual drainage obtained.

Statistical analysis was performed using the chi-square test, Student's t test, and analysis of variance (ANOVA). Statistical significance was assumed if $\mathrm{p}<0.05$.

\section{Results}

The cases included 438 males and 192 females (ratio 2.3:1), whose ages ranged from 12 to 100 years with a mean of 66.7 years. The etiology of CSDH was determined in 412 patients $(65.3 \%)$ and remained unclear in $218(34.7 \%)$. The interval from trauma to appearance of clinical symptoms was 30.4 days ( 25 days to 2 years). Of these, 389 had had trauma within the previous 4 months, while in 17 the period was longer than 1 year. The mean period from initial symptom to surgical treatment was 6.2 \pm 4.7 days.

Using the clinical grading scheme of Markwalder [2] for preoperative grading, 242 patients were grades $0-1$, 262 patients were grade 2 , and 126 patients were grades 3-4 (table 1). Predisposing factors included alcohol consumption (97 patients), the administration of anticoagulant or antiaggregant therapy (89 patients) and intracranial arachnoid cyst (6 cases, table 2). Nevertheless, none of these factors had a significant influence on the outcome.

The symptoms included focal neurological signs (aphasia, hemiparesis), 26 patients; increased intracranial pressure (headache, vomiting), 139 patients; mental anomalies, mainly dementia, 131 patients, and acute presentation of clinical symptoms with seizures or coma, 98 patients (table 2).

Clinical laboratory studies before surgery included bleeding time, platelet count, prothrombin time, and activated partial thromboplastin time. In 94 patients there were alterations of coagulation, 89 of which were patients receiving anticoagulant treatment and the remaining 5 with hematological diseases. Diagnosis of CSDH was confirmed by CT in all patients, including 32 patients with contrast-enhanced CT scans and 10 patients with MR imaging. The hematoma was right-sided in 234 (37.1\%), left-sided in $355(56.3 \%)$ and bilateral in 41 (6.5\%). Table 3 shows the classification according to the system developed by Lanksch et al. [3].

Surgery was performed with sedation and local anesthetic in 582 patients $(92.3 \%)$ and under general anesthetic in 48 patients $(7.7 \%)$. The initial surgical procedure included burr hole craniotomy. Subdural blood was evacuated by repeated irrigation with physiological saline, and all patients received one closed-system drain for 2-5 days. Drainage time depended on the amount of subdural fluid and brain reexpansion verified by CT control. In 41 patients with bilateral hematoma, the same technique was used bilaterally. There was no significant difference in outcome in the type of anesthesia, local versus general $(\mathrm{p}<0.05)$. Two patients had repeated surgery due to the appearance of a contralateral CSDH, which was not visible on the preoperative CT scan. The second operation also consisted of burr hole evacuation with subdural drainage.

The average stay in the Department of Neurosurgery was 8.3 days, ranging from 4 to 49 days; $74 \%$ of the patients were discharged within 2 weeks, $19 \%$ within 3 weeks, and the remainder in over 3 weeks. 
Table 2. Etiology, concomitant disease and first symptom of CSDHs

Table 3. CT according to the classification system developed by Lanksch et al. [3]

\begin{tabular}{lrrrr}
\hline & $<50$ years & $51-70$ years & $>71$ years & Total \\
\hline Etiology & & & & \\
$\quad$ Head injury & 165 & 181 & 66 & 412 \\
Anticoagulant-antiaggregant therapy & 12 & 47 & 30 & 89 \\
$\quad$ Coagulation disorder & 1 & 1 & 2 & 4 \\
\hline Concomitant disease & & & & \\
$\quad$ Alcohol abuse & 19 & 42 & 38 & 97 \\
Diabetes mellitus & 7 & 53 & 25 & 83 \\
Arterial hypertension & 11 & 84 & 31 & 125 \\
Arachnoid cyst & 4 & 2 & 0 & 6 \\
CSF shunt & 2 & 3 & 0 & 5 \\
\hline First symptom & & & & \\
$\quad$ Headache & 52 & 66 & 37 & 139 \\
Seizures & 17 & 26 & 21 & 64 \\
Behavioral disturbance & 19 & 47 & 59 & 131 \\
Hemisyndrome & 75 & 68 & 51 & 194 \\
Aphasia & 21 & 29 & 18 & 78 \\
Coma & 5 & 9 & 10 & 24 \\
\hline Total & 189 & 235 & 196 & 630 \\
\hline
\end{tabular}

\begin{tabular}{lrrrr}
\hline & $<50$ years & $51-70$ years & $>71$ years & Total \\
\hline Hematoma hypodense & 122 & 191 & 114 & 427 \\
Hematoma of varying density & 57 & 48 & 79 & 184 \\
Hematoma isodense & 29 & 8 & 14 & 41 \\
Hematoma slightly hyperdense & 4 & 7 & 8 & 19 \\
\hline
\end{tabular}

41 hematomas were bilateral.
Table 4. Admission grade and outcome (Markwalder grades)

\begin{tabular}{lrrrrrl}
\hline Admission grade & \multicolumn{7}{l}{ Outcome grade } \\
\cline { 2 - 6 } & 0 & 1 & 2 & 3 & 4 & exitus \\
\hline 0 & 12 & 0 & 0 & 0 & 0 & 0 \\
1 & 108 & 91 & 19 & 11 & 0 & 1 \\
2 & 123 & 88 & 33 & 13 & 2 & 3 \\
3 & 47 & 18 & 19 & 14 & 3 & 5 \\
4 & 1 & 3 & 5 & 2 & 2 & 7 \\
\hline
\end{tabular}

Table 4 presents the outcome of therapy in relation to the clinical grade at the time of admission. Both the deterioration of the level of consciousness and focal motor deficit were associated with an increased incidence of a
Table 5. Complications of treatment in relation to the clinical grade on admission

\begin{tabular}{|c|c|c|c|c|c|c|}
\hline \multirow[t]{2}{*}{ Results } & \multicolumn{5}{|c|}{ Clinical grade } & \multirow[t]{2}{*}{ Total } \\
\hline & 0 & 1 & 2 & 3 & 4 & \\
\hline $\mathrm{CSDH}$ recurrence & 1 & 9 & 13 & 9 & 2 & 34 \\
\hline Intracranial hypotension & 0 & 1 & 4 & 3 & 0 & 8 \\
\hline Subdural empyema & 1 & 0 & 1 & 2 & 1 & 5 \\
\hline Intracerebral hematoma & 0 & 1 & 1 & 1 & 0 & 3 \\
\hline Bronchopneumonia & 0 & 0 & 3 & 5 & 6 & 14 \\
\hline Tension pneumocephalus & 0 & 2 & 3 & 1 & 0 & 6 \\
\hline
\end{tabular}

poor outcome or mortality. Postoperative complications occurred in 70 patients. Table 5 compares the complications in relation to the clinical grade on admission. In 3 patients, routine evacuation of CSDH was followed by the 
Table 6. Factors affecting outcome $(n=630)$

\begin{tabular}{ll}
\hline Factor & Significance \\
\hline Grade at entrance: good/bad & $\mathrm{p}<0.001$ \\
Age (more 70) & $\mathrm{p}<0.05$ \\
Alcoholism & no significance \\
Anticoagulant therapy & no significance \\
Uni/bilateral CSDH & no significance \\
Anesthesia general/local & no significance \\
\hline
\end{tabular}

development of an ipsilateral intraparenchymatous hematoma; in 2 cases the hemorrhage was located in the brain, and in the remaining 1 in the brain stem. In these 3 cases the hemorrhages resolved gradually with no need for surgery. Five patients developed subdural empyema, treated in all cases by craniotomy.

Sixteen patients died in the hospital, a mortality rate of $2.5 \%$. Most of the patients who died were in clinical grade 3 or 4 (12 patients). Memory and personality defects were the most common residual deficits. There were no significant differences in the outcome of the 630 patients at hospital discharge in relation to the clinical grades on admission. However, there was a significant correlation between preoperative and postoperative grades. Patients with a good preoperative grade (grades 0-2 on the Markwalder scale) had a significantly better outcome than those presenting with a poor grade (grades $3-4, \mathrm{p}<0.001$, table 5).

\section{Discussion}

CSDH has been well known since the 17th century, with the review by Johann Wepfer [5a]. Later, in 1857, Virchow [5b] reported the same cases with the name of 'pachymeningitis haemorrhagia interna'. Since these reports, many authors have discussed the etiology, physiopathology and different treatments [6-8].

CSDHs occur most frequently in older patients. In this age-group, the brain weighs about $200 \mathrm{~g}$ less, which results in an increased extracerebral volume of up to $11 \%$ [8]. The male:female ratio in this series is $1.3: 1$, but in a majority of other series, the male:female ratio was revised to $2: 1$ [9-13]. The male preponderance may be due to (a) the greater exposure of males to injury, (b) fewer females seeking medical advice, and (c) estrogens may have a protective effect on the capillaries [13].

In this study, 97 (15\%) had a history of daily alcohol consumption. Similar results were reported by Sambasi- van [13] and Ernestus et al. [15]. The importance of alcoholism in the pathogenesis of CSDH has been studied by Sonne and Tønnesen [16], who observed that alcohol abusers have a significantly higher incidence of acute and chronic subdural hematomas, showed increased postoperative morbidity and mortality, and a poorer final outcome. Alcohol is known to impair the activity of the blood platelets, to increase fibrinolysis and diminish coagulation. Moreover, these patients have had many minor or mild head injuries.

The second predisposing factor was the use of drugs that modify coagulation. In this series, 58 patients $(9.8 \%)$ were antiaggregated with different products (aspirin, dicumarol, etc.) and $31(4.5 \%)$ were anticoagulated for previous cardiovascular diseases with warfarin or acenocumarol. In the series of Ernestus et al. [15] patients taking this medication represented only $5.6 \%$ while Villagrasa et al. [17] reported 15\%. In Jones and Kafetz's [10] study of 43 elderly patients, the incidence was $20 \%$. In younger patients, the predisposing factors are the presence of an arachnoid cyst [18] and hematological diseases [13]. However, in 347 patients (55\%) of this series, no predisposing factor was observed. In these patients, as in other series [9, $13,19], 65.3 \%$ had a history of head trauma, and in most of the cases the trauma was mild with a short period of unconsciousness. The interval between the trauma and surgery ranged from 10 days to 2 years. It is commonly believed that in older patients, the lapse between head trauma and the presentation of clinical symptoms is longer than in the young, presumably due to lower brain weight and larger subdural space [20]. No such correlation was observed in our CSDH group.

A CSDH is not a static entity, but a dynamic process. The first theory of the pathogenesis of CSDH was reported by Virchow [5], who linked minor head injury to 'pachymeningitis haemorrhagica interna'. In 1932 Gardner [21] proposed a hyperosmotic gradient across the subdural membranes resulting in progressive enlargement of the CSDH. However, actual measurements of the subdural fluid osmolality as well as other experimental work have not supported this theory. Current theory links the growth of a CSDH to the development of the vascular outer membrane. Yamashima and Yamamoto [22] have found proliferating macrocapillaries in the CSDH capsule. These authors have also reported mitotic activity of endothelial cells and vascular sprouts in the capsule, besides increased permeability. This accounts for recurrent bleeding and enlargement of the $\mathrm{CSDH}$. The high content of plasminogen and plasminogen activator within the outer neomembrane causes enzymatic fibrinolysis and 
liquefaction of the initial blood clot $[23,24]$. The new clots cannot provide effective hemostasis because they are rapidly lysed [25].

Fujisawa et al. [26] reported significantly high levels of bradykinin in CSDHs that indicate activation of the kallikrein-kinin system. The activation of this system, by increasing vascular permeability, may cause blood extravasation from the capillaries into the hematoma cavity resulting in enlargement of the hematoma. Recently, Suzuki et al. [27] found local elevation of inflammatory cytokines in the subdural space without systemic change, suggesting the presence of local inflammation in CSDHs. The authors believe that these higher levels of inflammatory cytokines may be involved in the continuous development of CSDHs. This situation results in frequent effusions of plasma or rebleeding from the neomembranes into the subdural collection. It is the ratio between effusion and rebleeding on the one hand, and reabsorption of the subdural collection on the other, which determines whether the CSDH will resolve, persist, increase in size or absorb spontaneously $[1,6]$.

Important differences in symptoms were not observed in relation to the age-groups. In previous reported series, focal neurological deficits account for $30-70 \%$ of the patients. In our series, only 282 patients $(44.7 \%)$ presented with neurological deficits. Symptoms of intracranial hypertension were present in almost $40 \%$ of patients with the same frequency in both young and elderly patients. This finding does not agree with other series that stress that older patients rarely have increased intracranial pressure due to cerebral atrophy [2].

CT scan remains the most important diagnostic procedure for CSDH although MR imaging has an advantage over CT scanning in terms of the image quality. The advantages of MR imaging over CT scanning in the evaluation of CSDHs are evident, especially in cases of isodense and bilateral CSDHs. However, MR imaging is a time-consuming, costly examination, and some elderly patients have cardiac pacemakers or metal implants [28].

Spontaneous resolution or medical treatment of CSDHs is well known, but in some reported series, the hospitalization ranged from 3 weeks to 42 days and some patients eventually required surgery $[29,30]$. Various surgical methods have been advocated for the treatment of CSDHs. At the beginning of the 20th century, Putnam and Cushing [31] discussed the pathology of CSDH and reported treatment with craniotomy. For many years, surgeons treated CSDHs by craniotomy and excision of the outer membrane, sometimes excising the inner membrane as well if this were not adherent to the brain. This technique has high operative mortality of up to $30 \%$ and is now rarely indicated, primarily for the treatment of repeated recurrence of the hematoma or solid consistency of the clot. McKissock et al. [32] were pioneers in the treatment of CSDH by simple burr hole drainage with an important reduction in mortality.

In 1977, Tabaddor and Shulman [33] proposed that slow continuous catheter drainage following twist-drill craniotomy offered substantial advantages in the treatment of CSDHs compared to the previous reported methods. Since then, some neurosurgeons have reported using burr hole or twist-drill craniotomy with [34] or without $[35,36]$ drainage as the first line of treatment. The most important problem is reaccumulation, mainly if the hematoma contains a solid or organized clot which cannot be cleared satisfactorily via burr hole or twist-drill. Several methods have been reported for reducing the amount of air remaining in the hematoma cavity and thus avoiding rebleeding. These include lumbar intrathecal injection of physiological saline or Ringer's solution during surgery $[12,37-39]$, the replacement of the hematoma with carbon dioxide gas [40] or oxygen [41], craniotomy without closure of the dura or replacing the bone plate [20], an implantation of a subcutaneous reservoir with a catheter introduced into the subdural cavity [41], or an overhydratation in the Trendelenburg position [2]. In 1988 Probst [43] reported a series of patients with CSDH treated by placement of a subdural-peritoneal shunt. The normalization of the CT scan occurred within 1-20 months after shunt placement. Recently, endoscopic techniques have been used to deal with blood reaccumulation without craniotomy. Endoscopic techniques were indicated in multiloculated or septated hematomas [44, 45]. In 1999 Arginteanu et al. [46] reported good results with the use of urokinase administered via the subdural drain in patients with blood reaccumulation in the subdural space after evacuation of the subacute subdural hematoma.

The other common complication is intracranial hypotension. Postoperative collapse of the brain and intracranial hypotension have often gone hand in hand, for in itself intracranial hypotension is associated with lowered states of consciousness, reversible when the pressure rises [12]. The incidence of postoperative intracranial hypotension was 3\% but in no case was there need for intrathecal or intraventricular injection of fluid, which has been advocated as a good method for producing the reexpansion of the brain [38]. McKissock et al. [32] reported decreased intracranial pressure in $3.3 \%$ of 212 patients with hematomas, but recently higher percentages (10\%) have been reported. 
Hematoma reoccurred in 34 patients and was treated by repeated irrigation and drainage of the hematoma cavity. Of the patients with recurrence, $23(3.6 \%)$ were older than 60 when cerebral atrophy was most pronounced. Other surgical complications included tension pneumocephalus [47] or the development of intracranial acute hematomas $[48,49]$.

A $4 \%$ incidence of postoperative epilepsy was found. Although in CT studies no cortical lesion or old hematoma was observed, we believe that the capsule which is left in situ may be responsible for late epilepsy [50]. Previous investigations in patients with CSDHs have reported rates ranging from 2 to $19 \%$ although the characteristics of the series or descriptions of seizure events varied widely. Sabo et al. [51] analyzed the role of prophylactic anticonvulsive medication in patients with CSDHs and found an incidence of $18.5 \%$ of new seizures in 92 patients. They concluded that patients with surgically treated CSDHs who received prophylactic phenytoin demonstrated a significant decrease in the occurrence of seizures and recommended its use for 6 months following the diagnosis and treatment of CSDH.

The mortality of chronic subdural hematoma treated by burr holes has been reported to range from 1.5 to $25 \%$ [12]. Over the last 25 years (the CT scan era) there has been a slow reduction in the mortality for the surgical treatment of CSDH. In 1976 Conomy et al. [52] reported a mortality of $20 \%$. Later, in 1980, Hubschmann [53] reported a mortality of $22.7 \%$ with twist drill and drainage. In recent series, the mortality ranged from 1.5 to $5 \%$ $[11,13,41]$. Twelve deaths occurred in patients admitted with severe neurological deficits and one was due to subdural empyema, which was a direct complication of surgery.

\section{Conclusion}

A burr hole with a closed drainage system is a simple, safe and efficient method for the treatment of CSDH. It appears that the only significant prognostic factor for the outcome of a patient with CSDH is the neurological condition at the time of diagnosis and treatment.

\section{Acknowledgment}

The authors thank Mr. R. Das Gupta for his assistance in the preparation of the manuscript.

\section{References}

1 Maurice-Williams RS: Chronic subdural hematoma: An everyday problem for the neurosurgeon. Br J Neurosurg 1999; 13:547-549.

2 Markwalder TM: Chronic subdural hematomas: A review. J Neurosurg 1981;54:637-645.

3 Lanksch W, Grumme T, Kazner E: Computed Tomography in Head Injuries. Berlin, Springer, 1979.

4 Jackson FE, Pratt RA: Technical report: A silicone rubber suction brain for drainage of subdural hematomas. Surgery 1971;70:578-579.

5a Cited by: Hoessly GF: Intracranial hemorrhage in the seventeenth century. J Neurosurg 1965; 24:493-496.

5b Virchow R: Das Hämatom der Dura mater. Verh Phys-Med Ges Würzb 1857;7:134-142.

6 Drapkin AJ: Chronic subdural hematoma: Pathophysiological basis for treatment. $\mathrm{Br} \mathrm{J}$ Neurosurg 1991;5:467-473.

7 Gelabert M: Hematoma subdural crónico en el anciano: Revisión de una serie de 53 casos. Geriatrika 1987;3:246-249.

8 Misra M, Salazar JL, Bloom DM: Subduralperitoneal shunt: Treatment for bilateral chronic subdural hematoma. Surg Neurol 1996;46:378-383.

9 Hamilton MG, Frizell JB, Tranmer BI: Chronic subdural hematoma: The role for craniotomy reevaluated. Neurosurgery 1993;33: 67-72.
10 Jones S, Kafetz K: A prospective study of chronic subdural haematomas in elderly patients. Age Ageing 1999;28:519-521.

11 Kotwica Z, Brzezinski J: Chronic subdural haematoma treated by burr holes and closed system drainage: Personal experience in 131 patients. Br J Neurosurg 1991;5:461-465.

12 Robinson RG: Chronic subdural hematoma: Surgical management in 133 patients. J Neurosurg 1984;61:263-268.

13 Sambasivan M: An overview of chronic subdural hematoma: Experience with 2,300 cases. Surg Neurol 1997;47:418-422.

14 Zingale A, Albanese V, Romano A, Distefano $\mathrm{G}$, Chiaramonte J: Traumatic chronic subdural hematoma over 80 years: A preliminary prospective study. J Neurosurg Sci 1997;41:169173.

15 Ernestus RI, Beldzinski P, Lanfermann H, Klug N: Chronic subdural hematoma: Surgical treatment and outcome in 104 patients. Surg Neurol 1997;48:200-225.

16 Sonne NM, Tønnesen H: The influence of alcoholism on outcome after evacuation of subdural haematoma. Br J Neurosurg 1992;6:125130 .
17 Villagrasa J, Prat R, Diaz FJ, Comunas F: Análisis de los factores pronósticos en pacientes adultos con hematoma subdural crónico. Neurologia 1998;13:120-124.

18 Parsch C, Krauss J, Hoffman E, Meixensberger J, Roosen K: Arachnoid cysts associated with subdural hematomas: Analysis of 16 cases, long-term follow-up, and review of the literature. Neurosurgery 1997;40:483-490.

19 Kotwica Z, Brzezinski J: Clinical pattern of chronic subdural haematoma. Neurochirurgia 1991;34:148-150.

20 Beatty RA: Subdural haematomas in the elderly: Experience with treatment by trephine craniotomy and not closing the dura or replacing the bone plate. Br J Neurosurg 1999;23:60-64.

21 Gardner WJ: Traumatic subdural hematoma with particular reference to the latent interval. Arch Neurol Psychiatry 1932;27:847-858.

22 Yamashima T, Yamamoto S: How do vessels proliferate in the capsule of chronic subdural hematoma? Neurosurgery 1984;15:672-677.

23 Fujisawa $H$, Ito $H$, Kashiwagi S, Nomura S, Toysawa M: Kallikrein-kinin system in chronic subdural haematomas: Its roles in vascular permeability and regulation of fibrinolysis and coagulation. J Neurol Neurosurg Psychiatry 1995;59:388-394. 
24 Ito H, Komai T, Yamamoto S: Fibrinolytic enzyme in the lining walls of chronic subdural hematoma. J Neurosurg 1978;48:197-200.

25 Labadie EL, Glover D: Local alterations of hemostatic-fibrinolytic mechanisms in reforming subdural hematomas. Neurology 1975;25: 669-675.

26 Fujisawa H, Ito H, Ikeda K, Nitta H, Yamashita J: Immunohistochemical localization of tissue-plasminogen activator in the lining wall of chronic subdural hematoma. Surg Neurol 1991;35:441-445.

27 Suzuki M, Endo S, Inada K, Kudo A, Kitakam A, Kuroda K, Ogawa A: Inflammatory cytokines locally elevated in chronic subdural haematoma. Acta Neurochir 1998;140:51-55.

28 Tsutsumi K, Maeda K, Iijima A, Usui M, Okada Y, Kirino T: The relationship of preoperative magnetic resonance imaging findings and closed system drainage in the recurrence of chronic subdural hematoma. J Neurosurg 1997;87:870-875.

29 Bender MB: The medical treatment of chronic subdural hematoma; in Morley TP (ed): Current Controversies in Neurosurgery. Philadelphia, Saunders, 1976, pp 556-560.

30 Suzuki J, Takaka A: Nonsurgical treatment of chronic subdural hematoma. J Neurosurg 1970;33:548-553.

31 Putman J, Cushing H: Chronic subdural hematoma: Its pathology, its relation to pachymeningitis haemorrhagica, and its surgical treatment. Arch Surg 1925;11:329-393.

32 McKissock W, Richardson A, Bloom WH: Subdural hematoma: A review of 389 cases. Lancet 1960;i:1360-1365.

33 Tabaddor K, Shulman K: Definitive treatment of chronic subdural hematoma by twist drill craniotomy and closed-system drainage. J Neurosurg 1977;46:220-226.
34 Camel M, Grubb RL: Treatment of chronic subdural hematoma by twist-drill craniotomy with continuous catheter drainage. J Neurosurg 1986;65:183-187.

35 Markwalder TM, Seiler RW: Chronic subdural hematomas: To drain or not to drain? Neurosurgery $1985 ; 26: 185-188$.

36 Suzuki K, Sugita K, Akai T: Treatment of chronic subdural hematoma by closed-system drainage without irrigation. Surg Neurol 1998; 50:231-234.

37 Ueno K, Murata J, Sakuma S, Takano K, Lizuka T: Intraoperative lumbar injection of Ringer's solution for surgical treatment of chronic subdural hematomas. Neurol Surg 1991;19: 511-516.

38 Grisoli F, Graziani N, Peragut JC, Vincentelli F, Fabrizi AP, Caruso G, Bellard S: Perioperative lumbar injection of Ringer's lactate solution in chronic subdural hematomas: A series of 100 cases. Neurosurgery 1988;23:616-621.

39 Gomez-Moreta JA, Morales F, Hernández J, Díaz P, Maillo A: Hematoma subdural crónico: Estudio de la expansión cerebral utilizando la inyección espinal de suero fisiológico durante la cirugía. Neurocirugía 1990;1:384-390.

40 Kitakami A, Ogawa A, Hakozaki S, Kidoguchi $\mathrm{J}$, Obonai $\mathrm{CH}$, Kubo N: Carbon dioxide gas replacement of chronic subdural hematoma using single burr-hole irrigation. Surg Neurol 1995;43:574-578.

41 Aoki N: A new therapeutic method for chronic subdural hematoma in adults: Replacement of the hematoma with oxygen via percutaneous subdural tapping. Surg Neurol 1992;38:253256.

42 Laumer R, Schramm J, Leykauf K: Implantation of a reservoir for recurrent subdural hematoma drainage. Neurosurgery 1989;25:991996.
43 Probst C: Peritoneal drainage of chronic subdural hematomas in older patients. J Neurosurg 1988;68:908-911.

44 Rodziewicz GS, Chuang WC: Endoscopic removal of organized chronic subdural hematoma. Surg Neurol 1995;43:569-573.

45 Hellwing D, Kuhn TJ, Bauer BL, List-Hellwig E: Endoscopic treatment of septated chronic subdural hematoma. Surg Neurol 1996;45: 272-277.

46 Arginteanu MS, Byun H, King W: Treatment of a recurrent subdural hematoma using urokinase. J Neurotrauma 1999;16:1235-1239.

47 Ishiwata Y, Fujitsu K, Sekino T, Fujino H, Kubokura T, Tsubone K, Kuwabara T: Subdural tension pneumocephalus following surgery for chronic subdural hematoma. J Neurosurg 1988;68:58-61.

48 Turgut M, Akalan, Sallam S: A fatal acute subdural hematoma occurring after evacuation of 'contralateral' chronic subdural hematoma. J Neurosurg Sci 1998;42:61-63.

49 Övül I, Öner K: Intracerebral hematoma after evacuation of chronic subdural hematoma. Neurochirurgia 1988;31:160-161.

50 Kotwica Z, Brzezinski J: Late results of surgical treatments of unilateral chronic subdural haematomas (in Polish). Pol Tyg Lek 1988;43: 737-738.

51 Sabo RA, Hanigan WC, Aldag JC: Chronic subdural hematomas and seizures: The role of prophylactic anticonvulsive medication. Surg Neurol 1995;43:579-582.

52 Conomy JP, Regula G, Mitsumoto H: Age as a determinant in the neurology of subdural hematomas. Trans Am Neurol Assoc 1976;101: 232-234.

53 Hubschmann OR: Twist drill craniotomy in the treatment of chronic and subacute subdural hematomas in severely ill and elderly patients. Neurosurgery 1980;6:233-236. 